\title{
Prognostic value of neutrophil to lymphocyte ratio in patients with colon cancer undergoing open and laparoscopic curative resection
}

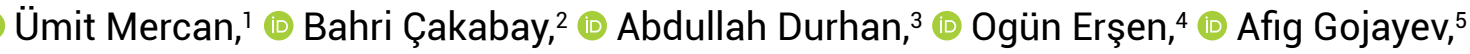 \\ (1) Ali Ekrem Ünal ${ }^{5}$ \\ 'Department of Surgical Oncology, Sanliurfa Mehmet Akif Inan Traninig and Research Hospital, Sanliurfa, Turkey \\ 2Department of Surgical Oncology, Diyarbakır Gazi Yasargil Training and Research Hospital, Diyarbakır, Turkey \\ ${ }^{3}$ Department of Surgical Oncology, Ankara Training and Research Hospital, Ankara, Turkey \\ ${ }^{4}$ Department of Surgical Oncology, Konya City Hospital, Konya, Turkey \\ ${ }^{5}$ Department of Surgical Oncology Ankara University Faculty of Medicine, Ankara, Turkey
}

\begin{abstract}
Introduction: It is known that many patient-related factors such as pre-operative nutritional status, comorbid diseases and especially the systemic inflammatory response affect post-operative outcomes and survival as much as the success of curative resection and the pathological stage. In the present study, it has been aimed to determine the effect of neutrophil to lymphocyte ratio (NLR) on post-operative and long-term results in patients with colon cancer who underwent laparoscopic curative resection.
\end{abstract}

Materials and Methods: Eligible 281 patient with colon adenocarcinoma underwent open and laparoscopic curative resection included in study. The patients were grouped as low and high NLR according to a cutoff NLR of 2.27 determined with receiver operating characteristic curve analysis and clinicopathological features, post-operative complications, and survival outcomes were compared.

Results: It was found that patients with high NLR had more advanced disease and there was a significant relationship between post-operative morbidity and high NLR. No significant relationship was found between overall and disease-free survival and NLR.

Conclusion: NLR, which can be measured by preoperative routine laboratory results, may be a simple, easily accessible prognostic biomarker in predicting the stage of the disease before surgery and identifying patients with high post-operative morbidity in patients with colon cancer. Considering that many factors affect long-term results, these data suggest that NLR, which is a marker that reflects the severity of the inflammatory response, is mostly associated with perioperative and short-term outcomes.

Keywords: Colon cancer, Laparoscopy, Lymphocyte, Neutrophil

\section{Introduction}

Although colon cancer has become diagnosed and treated at an early stage with the development of screening pro- grams today, it continues to be a public health problem that constitutes more than $10 \%$ of cancers diagnosed in the world. ${ }^{[1,2]}$ Despite the development in medical treat- 
ments and increasing surgical experience, $25 \%$ of patients die due to recurrence and distant metastases. It has been shown that many patients and tumor-related prognostic factors closely affect post-operative outcomes and survival in the broad spectrum between the excellent results obtained with laparoscopic surgery in the early stages and the development of widespread metastasis and recurrence in the advanced stages. ${ }^{[3]}$ Based on tumor depth, lymph node involvement rate and presence of distant organ metastasis, the tumor, node, and metastasis (TNM) system is the most commonly used parameter in staging patients, in adjuvant treatment decisions, and in determining prognosis. ${ }^{[4]}$ Surgical margin status, tumor budding, and lymphovascular invasion can also be counted as other tumor-associated prognostic factors whose effect and importance on results have been proven in many studies. ${ }^{[5]}$

It is known that many patient-related factors such as preoperative nutritional status and comorbid diseases affect post-operative outcomes and survival as much as the success of curative resection and the pathological stage. Especially in recent years, it has been proven that systemic inflammatory response has an important role in tumor growth and invasion development. The chronic inflammatory response that emerges as a result of the immune challenge between the tumor and the host triggers the migration of lymphocytes, monocytes, and neutrophils to the region. Although these cells try to create a barrier for tumor invasion, angiogenesis, which is perhaps the most important step in tumor growth, is stimulated as a result of many pro-inflammatory cytokines and inflammatory factors. ${ }^{[6]}$

Depending on the type of tumor and the patient's condition, varying degrees of systemic inflammatory response occurs but there is no marker that can accurately determine the extent of this response. Many scoring systems derived from markers such as C-reactive protein (CRP), procalcitonin, and albumin level or their combinations such as Modified Glasgow score and CRP to albumin ratio have been studied to measure the severity of the inflammatory response and determine its relationship with prognosis. ${ }^{[7,8]}$ In recent studies, it has been found that the neutrophil/lymphocyte ratio (NLR), which is an another indicator of the inflammatory response, is closely related to the prognosis in various cancer types such as ovarian cancer, cholangiocarcinomas, and pancreatic cancer, but the evidence in colon cancer is insufficient. ${ }^{[9-11]}$ Therefore, in this study, we aimed to determine the effect of pre-operative NLR on post-operative outcomes and long-term outcomes in colon cancer patients underwent open and laparoscopic curative resection.

\section{Materials and Methods}

Between January 2017 and January 2020, 281 patients who underwent laparoscopic curative resection with the diagnosis of colon adenocarcinoma at the Surgical Oncology Clinic of Ankara University were retrospectively analyzed. Patients whose data were not available, had metastatic disease at the time of diagnosis, had recurrent disease, had an emergent operation due to obstruction, perforation or bleeding, recently received antibiotic treatment for any reason, had hematological disease or immune deficit and received pre-operative chemotherapy or radiotherapy were excluded from the study.

Pre-operative routine hemogram and biochemistry values were recorded in all patients. Systemic inflammatory response was evaluated using NLR. NLR was determined with the values obtained from the pre-operative complete blood count and the optimal cutoff level was calculated as 2.27 with $70 \%$ sensitivity and 69\% specificity in Receiver operating characteristic (ROC) curve analysis (AUC: 0.73 95\% Confidence interval [CI]: 0.64-0.83. $\mathrm{P}=0.001>$ ). The patients were divided into two groups as below and above this value.

Tumor and lymph node status of the patients were determined based on the American Joint Committee on Cancer $8^{\text {th }}$ edition: Colon cancer study. ${ }^{[4]}$ Post-operative complications were determined on the basis of the Modified Clavien Dindo Classification, and the presence of Grade 3 or higher complications was evaluated. ${ }^{[12]}$ The relationship between NLR and postoperative serious complications and survival was analyzed.

Approval was obtained from the Ethics Committee of Ankara University Faculty of Medicine. Approval date and number: 16.01.2020, 11-37-20.

\section{Statistical Analysis}

Numerical values were expressed as mean \pm standard deviation or percentages. Histogram graphics and Kolmogorov-Smirnov test were used to determine the normal distribution of numerical variables. In comparison of demographic and clinicopathological variables between the groups; Student's T-test or Mann-Whitney U-test 
were used for numerical variables; $\chi^{2}$ test or Fisher Exact Test for categorical variables. The optimal cutoff level of the NLR was determined by ROC analysis. Binary logistic regression analysis was used to determine the factors affecting post-operative complications. Cox proportional regression model with backward elimination stepwise approach was used for multivariate analysis of overall survival (OS). All $\mathrm{P}<0.05$ were considered statistically significant. These analyzes were performed using IBM® SPSS statistic version 23.0.

\section{Results}

The comparison of clinicopathological variables, postoperative, and long-term results between the groups of NLR is summarized in Table 1. The mean age of 281 patients included in the study was 59.1 \pm 7.96 and 181 (64.4) of the patients were male. There were 177 patients in the low NLR group and 104 patients in the high NLR group. $209(74.4 \%)$ patients diagnosed with the left colon cancer and the most common operation was sigmoid colectomy (47.3\%). There was no significant difference between the groups in terms of age, gender, American society of anesthesiology (ASA) score, type of operation, tumor location, and preoperative CEA level. T stage, lymph node status, and TNM stages were significantly different between the groups and it was observed that the patients in the group of high NLR had more advanced stage tumors ( $\mathrm{p}=0.001>$; $\mathrm{p}=0.005$; and $\mathrm{p}=0.001>$ ).

There was no statistically significant difference between the groups in terms of operation time, general and in hospital mortality rates, anastomotic leakage, and recurrence or metastasis rates. Hospital and intensive care stay were significantly longer in the group of high NLR ( $p=0.001>$; and $\mathrm{p}=0.001>$ ). Post-operative serious complications were observed with a rate of $28.8 \%$ in the group of high NLR while this rate was $7.6 \%$ in the group of low NLR ( $p=0.001)$.

The univariate and multivariate analysis results of risk factors associated with the development of post-operative serious complications are summarized in Table 2. In univariate analysis, advanced TNM stage (Odds ratio [OR]: $2.1195 \%$ CI: 1.02 4.38 p=0.028) and high NLR (OR: 4.72 95\% CI: 2.36 9.42 $\mathrm{p}=0.001>$ ) were found to have a statistically significant effect on serious postoperative complications. In multivariate regression analysis, NLR (OR: 0.41 95\% CI: 0.18 0.91 p=0.029) was found to be an independent predictor of serious post-operative complications.

The cumulative survival rate was $92 \%$ at the $1^{\text {st }}$ year and
$76.9 \%$ at the $3^{\text {rd }}$ year. In general patient population, the mean OS was 35.19 \pm 0.75 (95\% CI: 33.72 36.66) months and the mean disease-free survival (DFS) was 34.07 \pm 0.79 (95\% CI: 32.52 35.63) months. Mean OS in high and low NLR groups were $33.78 \pm 1.34$ (95\% CI: 31.11 36.44) and $35.78 \pm 0.87$ (95\% CI: 34.07 37.50) months, respectively, and there was no statistically significant difference $(\mathrm{p}=0.167)$ (Fig. 1). Mean DFS were found as $32.77 \pm 1.38$ (95\% CI: 30.06 35.47) months in high NLR group and 34.51 \pm 095 (95\% CI: 32.64 36.38) months in low NLR group and similarly no statistically significant difference was observed ( $p=0.240)$ (Fig. 2).

In the Cox regression analysis of risk factors affecting OS, age $>65$ years (Hazard ratio [HR]: 1.65 95\% CI: 1.28 4.49 $\mathrm{p}=0.016$ ), advanced TNM stage (HR: $0.0795 \%$ CI: 0.01 0.32 $\mathrm{p}=0.012$ ), and post-operative serious complications (HR: 0.20 95\% CI: 0.09 0.44 $\mathrm{p}=0.038$ ) were found to be independent risk factors (Table 3 ).

\section{Discussion}

Pre-operative staging and post-operative treatment plan of non-metastatic colon cancer diseases are usually arranged according to the TNM staging system. However, there are still prognostic differences between patients with the same stage. ${ }^{[13]}$ Therefore, even after adjuvant chemotherapy for surgical resections and similar stages, local recurrence, and distant metastasis may develop in some patients. It is increasingly accepted that variations in disease course and clinical outcome in colorectal cancer patients are affected not only by the oncological features of the tumor itself but also by host response factors. ${ }^{[14]}$ Recent studies have shown an association between inflammatory response and clinical outcomes in various cancers. ${ }^{[15-17]}$

In general, studies have explained that lymphopenia means impaired cell-mediated immunity, while neutrophilia is associated with the response to systemic inflammation. ${ }^{[18]}$ It has been reported that patients with high-density lymphocytes in the stroma of the tumors have better clinical outcomes compared to low-density lymphocytes. ${ }^{[19,20]}$ The inflammatory response causes changes in the levels of circulating white blood cells, including neutrophils, and lymphocytes. However, day-related fluctuations in neutrophil count are not always in line with lymphocytes. ${ }^{[21]}$ Therefore, the relative value of a composite index such as the NLR may more precisely reflect the antitumor activity of the host immune system. 
Table 1. Comparison of clinicopathological variables. Post-operative and long-term results between the groups of NLR

Variables

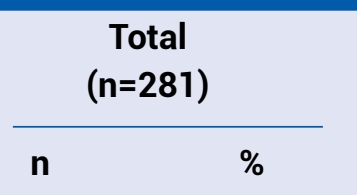

\section{High NLR (>2.27)}

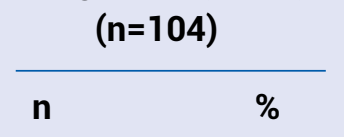

\section{Low NLR (2.27>)}

\begin{tabular}{ll}
\multicolumn{3}{c}{$(n=177)$} & \\
\hline$n$ & $\%$
\end{tabular}

\begin{tabular}{|c|c|c|c|c|c|c|c|}
\hline \multirow{2}{*}{$\begin{array}{l}\text { Age } \\
\text { Gender (male) }\end{array}$} & \multicolumn{2}{|c|}{$59.1 \pm 7.96$} & \multicolumn{2}{|c|}{$59.4 \pm 7.69$} & \multicolumn{2}{|c|}{$58.9 \pm 7.69$} & \multirow{2}{*}{$\begin{array}{l}0.624 \\
0.609\end{array}$} \\
\hline & 181 & 64.4 & 65 & 62.5 & 116 & 65.5 & \\
\hline \multicolumn{8}{|l|}{ ASA } \\
\hline 1 & 67 & 23.8 & 20 & 19.2 & 47 & 26.6 & \multirow[t]{3}{*}{0.278} \\
\hline 2 & 141 & 50.2 & 58 & 55.8 & 83 & 46.9 & \\
\hline 3 & 73 & 26 & 26 & 25 & 47 & 26.6 & \\
\hline \multicolumn{8}{|l|}{ Operation type } \\
\hline $\mathrm{RH}$ & 65 & 23.1 & 24 & 23.1 & 41 & 23.2 & \multirow[t]{5}{*}{0.241} \\
\hline $\mathrm{eRH}$ & 7 & 2.5 & 4 & 3.8 & 3 & 1.7 & \\
\hline $\mathrm{LH}$ & 16 & 5.7 & 2 & 1.9 & 14 & 7.9 & \\
\hline $\mathrm{eLH}$ & 60 & 21.4 & 23 & 22.1 & 37 & 20.9 & \\
\hline SR & 133 & 47.3 & 51 & 49 & 82 & 46.3 & \\
\hline \multicolumn{8}{|l|}{ Tumor location } \\
\hline Right colon & 72 & 25.6 & 28 & 26.9 & 44 & 24.9 & \multirow[t]{2}{*}{0.403} \\
\hline Left colon & 209 & 74.4 & 76 & 73.1 & 133 & 75.1 & \\
\hline \multicolumn{8}{|l|}{ T stage } \\
\hline $\mathrm{T} 1$ & 18 & 6.4 & 0 & 0 & 18 & 10.2 & \multirow[t]{4}{*}{$0.001>$} \\
\hline $\mathrm{T} 2$ & 51 & 18.1 & 7 & 6.7 & 44 & 24.9 & \\
\hline T3 & 132 & 47 & 56 & 53.8 & 76 & 42.9 & \\
\hline T4 & 80 & 28.5 & 41 & 39.4 & 39 & 22 & \\
\hline \multicolumn{8}{|l|}{$\mathrm{N}$ stage } \\
\hline NO & 110 & 39.1 & 28 & 26.9 & 82 & 46.3 & 0.005 \\
\hline N1 & 90 & 32 & 41 & 39.4 & 49 & 27.7 & \\
\hline N2 & 81 & 28.8 & 35 & 33.7 & 46 & 26 & \\
\hline TNM stage* & & & & & & & $<0.001$ \\
\hline Stage 1 & 56 & 19.9 & 6 & 5.8 & 50 & 28.2 & \\
\hline Stage 2 & 53 & 18.9 & 21 & 20.2 & 32 & 18.1 & \\
\hline Stage 3 & 172 & 61.2 & 77 & 74 & 95 & 53.7 & \\
\hline CEA (ng/ml) & \multicolumn{2}{|c|}{$29.68 \pm 13.14$} & \multicolumn{2}{|c|}{$30.19 \pm 12.54$} & \multicolumn{2}{|c|}{$28.25 \pm 13.43$} & 0.843 \\
\hline Operation time (min) & \multicolumn{2}{|c|}{$145.21 \pm 54.25$} & \multicolumn{2}{|c|}{$144.57 \pm 58.49$} & \multicolumn{2}{|c|}{$146.03 \pm 57.15$} & 0.196 \\
\hline Hospital stay (day) & \multicolumn{2}{|c|}{$8.54 \pm 3.50$} & \multicolumn{2}{|c|}{$9.60 \pm 4.10$} & \multicolumn{2}{|c|}{$7.93 \pm 2.95$} & $<0.001$ \\
\hline ICU stay (day) & \multicolumn{2}{|c|}{$1.58 \pm 1.36$} & \multicolumn{2}{|c|}{$1.88 \pm 1.54$} & \multicolumn{2}{|c|}{$1.40 \pm 1.21$} & $<0.001$ \\
\hline $\begin{array}{l}\text { General mortality } \\
\text { (number of patients) }\end{array}$ & 41 & 14.6 & 19 & 18.3 & 22 & 12.4 & 0.123 \\
\hline $\begin{array}{l}\text { In hospital mortality } \\
\text { (number of patients) }\end{array}$ & 6 & 2.1 & 3 & 2.9 & 3 & 1.7 & 0.673 \\
\hline $\begin{array}{l}\text { Post-operative } \\
\text { complications }(C D \geq 3) * *\end{array}$ & 44 & 15.7 & 30 & 28.8 & 14 & 7.9 & $<0.001$ \\
\hline Anastomotic leakage & 12 & 4.3 & 6 & 5.8 & 6 & 3.4 & 0.370 \\
\hline Recurrence/metastasis & 50 & 17.8 & 21 & 20.2 & 29 & 16.4 & 0.258 \\
\hline
\end{tabular}

Numerical values are given as mean \pm standard error or percentages. NLR: Neutrophil to lymphocyte ratio; ASA: American society of anesthesiologists; RH: Right hemicolectomy; eRH: Extended right hemicolectomy; LH: Left hemicolectomy; eLH: Extended left hemicolectomy; SR: Sigmoid resection; TNM: Tumor, Node, Metastasis; CEA: Carcinoembrionic antigene; ICU: Intensive care unit; CD: Clavien-Dindo; *TNM stage, tumor and lymph node status of the patients were determined based on the American Joint Committee on Cancer (AJCC) 8th edition: colorectal cancer study. ${ }^{[4]} * *$ Post-operative complications were categorized according to the Modified Clavien Dindo classification. ${ }^{[12]}$ 
Table 2. Univariate and multivariate analysis of risk factors associated with serious post-operative complications

Variable
Univariate analysis

OR $(95 \% \mathrm{Cl}) \quad \mathrm{p}$

Multivariate analysis

Adjusted OR

$(95 \% \mathrm{Cl})$

\begin{tabular}{lcccc}
\hline Age $(>65)$ & $1.15(0.54 \sim 2.44)$ & 0.417 & - & - \\
High ASA score & $1.23(0.60 \sim 2.51)$ & 0.338 & - & - \\
Advanced TNM stage & $2.11(1.02 \sim 4.38)$ & $0.028 *$ & - & - \\
High NLR & $4.72(2.36 \sim 9.42)$ & $<0.001 *$ & $0.41(0.18 \sim 0.91)$ & 0.029
\end{tabular}

OR: Odds ratio; CI: Confidence interval; ASA: American society of anesthesiology; TNM: Tumor, Nod, Metastasis; NLR: Neutrophil to lymphocyte ratio.

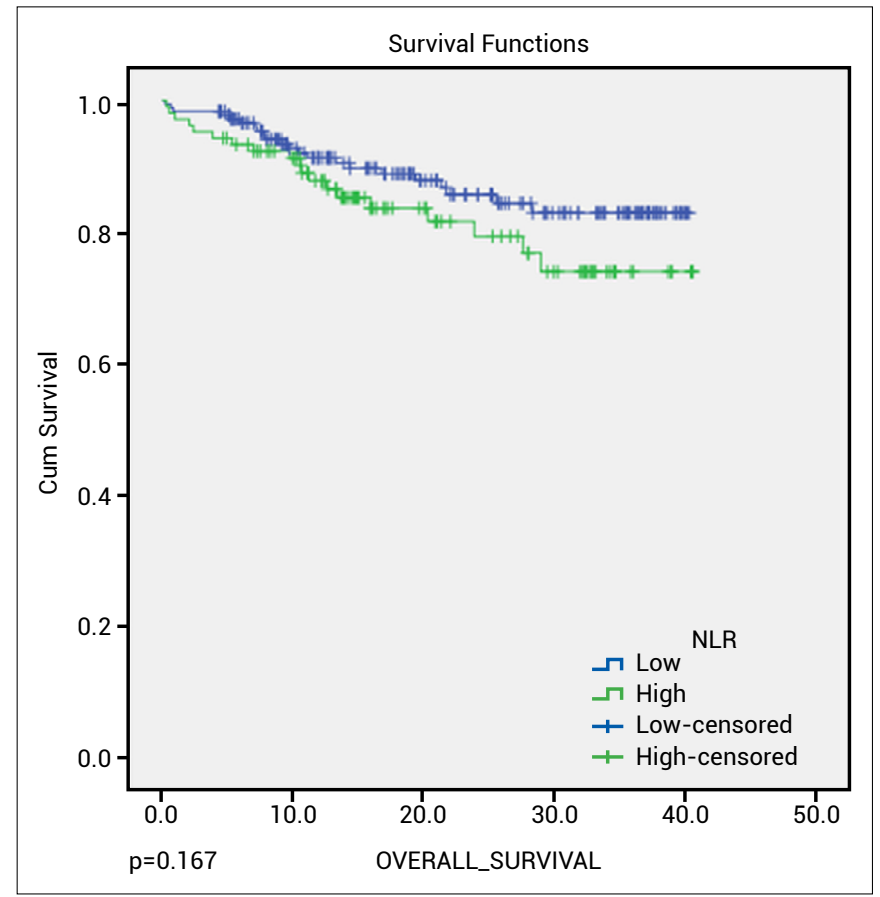

Figure 1. Kaplan-Meier survival curves comparing overall survival rates between neutrophil to lymphocyte ratio groups.

The NLR has been used not only as a marker of inflammation but also as a prognostic index for various malignancies. ${ }^{[22-25]}$

There is no definite value determined for NLR and different cutoff values obtained by many different methods have been used in the literature. While the cutoff value for preoperative NLR was 2.27 in our study, it was determined as $3,{ }^{[13,26]} 5,{ }^{[27]}$ or $2.2^{[28]}$ in different studies.

In the present study, a significant relationship was found between NLR and clinicopathological features, similar to the literature. High NLR was significantly associated with advanced T stage, $\mathrm{N}$ stage and TNM stage, severe post-op-

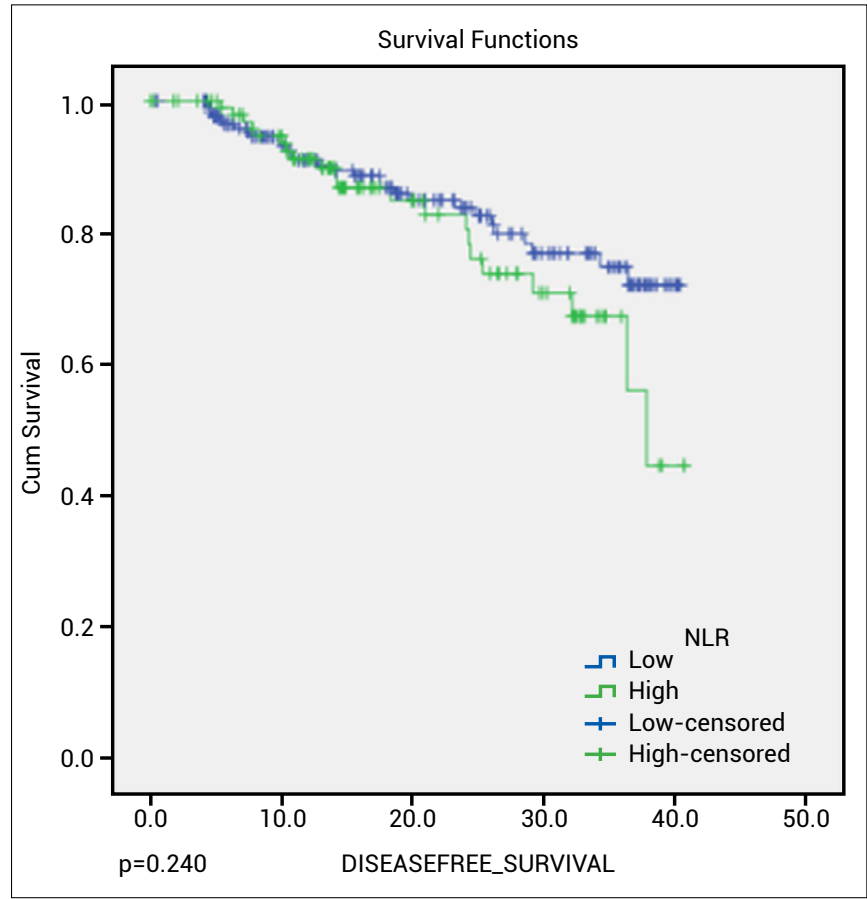

Figure 2. Kaplan-Meier survival curves comparing disease-free survival rates between neutrophil to lymphocyte ratio groups.

erative complications, and length of stay in hospital and intensive care.

Many studies have examined the predictive effect of NLR on disease burden and patient prognosis. ${ }^{[29,30]}$ The TNM staging system determined by AJCC and based on postoperative pathological classification is the most widely accepted and clinically used method to determine the probability of a patient's cure from cancer. The stage of the tumor is also used to make recommendations for the need and type of chemotherapy. In addition, a number of other tumor markers with prognostic implications have been evaluated by pathologists. It has been suggested 
Table 3. Cox regression analysis of risk factors affecting overall survival

\begin{tabular}{lcc} 
Variables & \multicolumn{2}{c}{ Cox regression analysis } \\
\cline { 2 - 3 } & HR $(95 \% \mathrm{Cl})$ & $\mathbf{p}$ \\
\hline Age $(>65)$ & $1.65(1.28 \sim 4.49)$ & 0.016 \\
Gender (male) & $1.06(0.43 \sim 1.85)$ & 0.465 \\
High ASA score & $1.14(0.52 \sim 2.53)$ & 0.732 \\
Advanced TNM stage & $0.07(0.01 \sim 0.32)$ & 0.012 \\
CD $\geq 3$ post-operative complications & $0.20(0.09 \sim 0.44)$ & 0.038 \\
High NLR $(>2.27)$ & $1.31(0.62 \sim 2.79)$ & 0.475 \\
\hline
\end{tabular}

HR: Hazard ratio; Cl: Confidence interval; ASA: American society of anesthesiology; TNM: Tumor, Node, Metastasis; CD: Clavien Dindo; NLR: Neutrophil to lymphocyte ratio.

that early signs of metastasis such as lymphovascular and perineural invasion be used in clinical practice to guide targeted chemotherapy and immunotherapy. ${ }^{[31]}$ While TNM classification is a post-operative staging, determining easy-to-apply, inexpensive, and reproducible predictive factors such as NLR may guide clinicians in pre-operative staging of the disease and treatment planning. In the present study, a statistically significant relationship was found between high NLR and advanced TNM stages.

A significant correlation was found between high NLR and post-operative increased morbidity (length of stay in hospital and intensive care unit and development of postoperative serious complications). This prognostic value provides important information to the clinician about the patient in the pre-operative period and may be a predictive value that can ensure that necessary measures are taken to reduce morbidity during the preparation process and surgery.

While advanced age, advanced TNM stage and Clavien Dindo 3 and above serious complications were found to be independent risk factors for survival, no statistically significant relationship was found between NLR and OS or DFS. In the literature, there are different results in terms of the relationship between high NLR and survival. Walsh et al. found an association between high NLR and decreased OS in colon cancer patients at all stages. ${ }^{[29]}$ In another meta-analysis involving colorectal cancer patients, a high NLR was associated with decreased OS in colon cancer patients, while no significant association was found in the rectal cancer subgroup. ${ }^{[13]}$ In the study conducted by Chen et al., no statistically significant relationship was found between high NLR and decreased OS. ${ }^{[23]}$ Our study results and different results in the literature suggest that NLR is mostly associated with short-term outcomes and post-operative morbidity.

The main limitations of the study are possible selection bias due to being of a single center retrospective study and relatively low sample size. Due to insufficient data, we did not have the chance to evaluate medical conditions that could affect the patients' immune system. It is also possible that the high NLR levels were confused by some unmeasured covariates.

\section{Conclusion}

NLR, which can be measured by preoperative routine laboratory results, may be a simple, easily accessible prognostic biomarker in predicting the stage of the disease before surgery and identifying patients with high postoperative morbidity in patients with colon cancer. Considering that many factors affect long-term results, these data suggest that NLR, which is a marker that reflects the severity of the inflammatory response, is mostly associated with perioperative and short-term outcomes. Prospective randomized large-scale studies are needed to determine the effect of NLR on OS and DFS.

\section{Disclosures}

Ethichs Committee Approval: Approval was obtained from the Ethics Committee of Ankara University Faculty of Medicine. Approval date and number: 16.01.2020, 11-37-20.

Peer-review: Externally peer-reviewed.

Conflict of Interest: None declared. 
Authorship Contributions: Concept - Ü.M; Design Ü.M; Supervision - B.Ç; Materials - A.G.; Data Collection and/or processing - O.E.; Analysis and/or interpretation - Ü.M.; Literature search - A.D.; Writing - Ü.M., A.D.; Critical review - AE.Ü.

\section{References}

1. Haggar FA, Boushey RP. Colorectal cancer epidemiology: İncidence, mortality, survival, and risk factors. Clin Colon Rectal Surg 2009;22:191-7. [CrossRef]

2. Aran V, Victorino AP, Thuler LC, Ferreira CG. Colorectal cancer: Epidemiology, disease mechanisms and interventions to reduce onset and mortality. Clin Colorectal Cancer 2016;15:195-203. [CrossRef]

3. Dimofte G, Târcoveanu E, Taraşi M, Panait C, Lozneanu G, Nicolescu $S$, et al. Mean number of lymph nodes in colonic cancer specimen: Possible quality control index for surgical performance. Chirurgia (Bucur) 2011;106:759-64.

4. Weiser MR. AJCC 8th Edition: Colorectal cancer. Ann Surg Oncol 2018;25:1454-5. [CrossRef]

5. Panait L, Suresh S, Fancher TT, Singh-Braich P, Sim Y, Dudrick SJ. Do laparoscopic colectomy techniques compromise oncologic principles? Chirurgia 2011;106:475-8.

6. Grivennikov SI, Greten FR, Karin M. Immunity, inflammation, and cancer. Cell 2010;140:883-99. [CrossRef]

7. Guthrie GJ, Charles KA, Roxburgh CS, Horgan PG, McMillan DC, Clarke SJ. The systemic inflammation-based neutrophillymphocyte ratio: Experience in patients with cancer. Crit Rev Oncol Hematol 2013;88:218-30. [CrossRef]

8. Dolan RD, Laird BJ, Horgan PG, McMillan DC. The prognostic value of the systemic inflammatory response in randomised clinical trials in cancer: A systematic review. Crit Rev Oncol Hematol 2018;132:130-7. [CrossRef]

9. Buettner S, Spolverato G, Kimbrough CW, Alexandrescu S, Marques HP, Lamelas J, et al. The impact of neutrophil-tolymphocyte ratio and platelet-to-lymphocyte ratio among patients with intrahepatic cholangiocarcinoma. Surgery 2018;164:411-8. [CrossRef]

10. Farolfi A, Petrone M, Scarpi E, Galla V, Greco F, Casanova $C$, et al. Inflammatory indexes as prognostic and predictive factors in ovarian cancer treated with chemotherapy alone or together with bevacizumab. A multicenter, retrospective analysis by the Mito group (Mito 24). Target Oncol 2018;13:469-79. [CrossRef]

11. Glazer ES, Rashid OM, Pimiento JM, Hodul PJ, Malafa MP. Increased neutrophil-to-lymphocyte ratio after neoadjuvant therapy is associated with worse survival after resection of borderline resectable pancreatic ductal adenocarcinoma. Surgery 2016;160:1288-93. [CrossRef]

12. Dindo D, Demartines N, Clavien PA. Classification of surgical complications: A new proposal with evaluation in a cohort of 6336 patients and results of a survey. Ann Surg 2004;240:205-13. [CrossRef]
13. Chiang SF, Hung HY, Tang R, Changchien CR, Chen JS, You YT, et al. Can neutrophil-to-lymphocyte ratio predict the survival of colorectal cancer patients who have received curative surgery electively? Int J Colorectal Dis 2012;27:1347-57. [CrossRef]

14. Shin R, Jeong SY, Yoo HY, Park KJ, Heo SC, Kang GH, et al. Depth of mesorectal extension has prognostic significance in patients with T3 rectal cancer. Dis Colon Rectum 2012;55:1220-8. [CrossRef]

15. Roxburgh CS, McMillan DC. Role of systemic inflammatory response in predicting survival in patients with primary operable cancer. Future Oncol 2010;6:149-63. [CrossRef]

16. Lee YY, Choi CH, Kim HJ, Kim TJ, Lee JW, Lee JH, et al. Pretreatment neutrophil:lymphocyte ratio as a prognostic factor in cervical carcinoma. Anticancer Res 2012;32:155561.

17. Pichler $M$, Hutterer GC, Stoeckigt C, Chromecki TF, Stojakovic T, Golbeck $S$, et al. Validation of the pre-treatment neutrophil-lymphocyte ratio as a prognostic factor in a large European cohort of renal cell carcinoma patients. $\mathrm{Br} \mathrm{J}$ Cancer 2013;108:901-7. [CrossRef]

18. Zahorec R. Ratio of neutrophil to lymphocyte counts-rapid and simple parameter of systemic inflammation and stress in critically ill. Bratisl Lek Listy 2001;102:5-14.

19. Clark EJ, Connor S, Taylor MA, Madhavan KK, Garden OJ, Parks RW. Preoperative lymphocyte count as a prognostic factor in resected pancreatic ductal adenocarcinoma. HPB (Oxford) 2007;9:456-60. [CrossRef]

20. Teramukai S, Kitano T, Kishida Y, Kawahara M, Kubota K, Komuta $K$, et al. Pretreatment neutrophil count as an independent prognostic factor in advanced non-small-cell lung cancer: An analysis of Japan multinational trial organisation LC00-03. Eur J Cancer 2009;45:1950-8. [CrossRef]

21. Suzuki S, Toyabe S, Moroda T, Tada T, Tsukahara A, liai T, et al. Circadian rhythm of leucocytes and lymphocytes subsets and its possible correlation with the function of the autonomic nervous system. Clin Exp Immunol 1997;110:5008. [CrossRef]

22. Pine JK, Morris E, Hutchins GG, West NP, Jayne DG, Quirke $\mathrm{P}$, et al. Systemic neutrophil-to-lymphocyte ratio in colorectal cancer: The relationship to patient survival, tumour biology and local lymphocytic response to tumour. $\mathrm{Br} \mathrm{J}$ Cancer 2015;113:204-11. [CrossRef]

23. Chen JH, Zhai ET, Yuan YJ, Wu KM, Xu JB, Peng JJ, et al. Systemic immune-inflammation index for predicting prognosis of colorectal cancer. World J Gastroenterol 2017;23:626172. [CrossRef]

24. Absenger G, Szkandera J, Stotz M, Postlmayr U, Pichler M, Ress $A L$, et al. Preoperative neutrophil-to-lymphocyte ratio predicts clinical outcome in patients with stage II and III colon cancer. Anticancer Res 2013;33:4591-4.

25. Cedres S, Torrejon D, Martinez A, Martinez $P$, Navarro A, Zamora $E$, et al. Neutrophil to lymphocyte ratio (NLR) as an indicator of poor prognosis in stage IV non-small cell lung cancer. Clin Transl Oncol 2012;14:864-9. [CrossRef] 
26. Malietzis G, Giacometti M, Askari A, Nachiappan S, Kennedy $\mathrm{RH}$, Faiz OD, et al. A preoperative neutrophil to lymphocyte ratio of 3 predicts disease-free survival after curative elective colorectal cancer surgery. Ann Surg 2014;260:287-92. [CrossRef]

27. Walsh SR, Cook EJ, Goulder F, Justin TA, Keeling NJ. Neutrophil-lymphocyte ratio as a prognostic factor in colorectal cancer. J Surg Oncol 2005;91:181-4. [CrossRef]

28. Ozdemir Y, Akin ML, Sucullu I, Balta AZ, Yucel E. Pretreatment neutrophil/lymphocyte ratio as a prognostic aid in colorectal cancer. Asian Pac J Cancer Prev 2014;15:2647-50. [CrossRef]

29. Oh SY, Kim YB, Suh KW. Prognostic significance of systemic inflammatory response in stage II colorectal cancer. J Surg Res 2017;208:158-65. [CrossRef]

30. Jia J, Zheng X, Chen Y, Wang L, Lin L, Ye X, et al. Stage-dependent changes of preoperative neutrophil to lymphocyte ratio and platelet to lymphocyte ratio in colorectal cancer. Tumour Biol 2015;36:9319-25. [CrossRef]

31. Pages F, Berger A, Camus M, Sanchez-Cabo F, Costes A, Molidor $\mathrm{R}$, et al. Effector memory $\mathrm{T}$ cells, early metastasis, and survival in colorectal cancer. N Engl J Med 2005;353:265466. [CrossRef] 